\title{
Social Ecology and Rural Development in Northeast India: Challenges \& Opportunities in Manipur
}

\author{
Cheithou Charles Yuhlung \\ Dept. of Sociology, Women's College, Shillong, Meghalaya, India - 793003
}

\begin{abstract}
This paper focuses on the critical depletion of social ecology in relation to developmental works carried out especially in Manipur. It points out that due to the increasing developmental demands and deforestation, the rural people, whose main source of income depends on natural resources like forests produce are threatening their very own survival. The then existing thick and dense forests with diverse flora and fauna has substantially declined due to overwhelming demand of supply like timber and firewood for various developmental purposes affecting the social ecology, food-chains and even leading to scarcity of drinking water. It also points out the deprivation of the rural tribal people, failure and weaknesses on the part of the government machineries in protecting and uplifting the rural people, its environment and the need for proper study to preserve the rural forests. It seeks the government's intervention in controlling the reserved and protected tribal forest areas of Northeast India. The paper also stresses on the preservation of indigenous plants and the use of selected plants for the afforestation programs in the region.
\end{abstract}

Keywords: Ecology, Depletion, Deforestation, Rural Development, Indigenous plants, Food-chain, Water Scarcity.

\section{Introduction}

Social ecology may be understood as the balance of inter-relationship between organisms and their environment. The Concise Oxford Dictionary defines, "Ecology as the branch of biology dealing with the relations of organisms to one another and to their physical surrounding, or the study of the interaction of people with their environment". This definition suggests that the social ecology is the interaction of human beings with their physical environment. Social ecology advocates a reconstructive and transformative outlook on social and environmental issues. It envisions a moral economy that acts beyond scarcity and threats towards a world that would re-harmonize human communities with the natural world, while celebrating diversity, creativity and freedom. It also promotes conservation and preservation of natural environment while uplifting the sustainability of the people.

The North-Eastern States although, have low living standards and poor Gross State Domestic Product (GSDP) is richly blessed with natural biodiversity, and the region is identified as one of the world's biodiversity hotspots. It hosts species-rich tropical rain forests and supports diverse flora and fauna and several crop species. ${ }^{1}$ This rich biodiversity is identified not only in terms of natural resources but socially and culturally as well. Hence, social anthropologists term the region as cultural hotspot due to the presence of diverse ethnic groups and sub-groups or tribes and sub-tribes. However, the present scenario has shown that the world's biodiversity hotspot zone is under a serious threat from excessive human exploitation of natural resources and gradual deforestation resulting in imbalances in the ecology and decline in flora and fauna. The impact is worst felt in the rural areas creating certain major social issues and posing tremendous challenges in rural sustainable development in the Northeast region, especially Manipur.

Manipur is a small hilly state, located on the extreme part of the North-eastern region of India. It is one of the most unproductive and politically torn states in the region. The state covers a total geographical area of about $22,327 \mathrm{sq} \mathrm{km}^{2}$. There are nine districts, of which five are hill districts that surround the other four valley districts. $^{3}$ All the five hill districts or hills of Manipur occupy approximately $90 \%$ of the total area of the state, whereas the valley (four districts) occupies only about 2,238 sq.km i.e. less than $10 \%{ }^{4}$ The Census of India 2011 indicates that the majority of the population of Manipur lived in rural area which is about $69.79 \%$, as compared to $30.21 \%$ living in urban area. Broadly, Manipur forest area is divided into three categories as, (i) Reserved forest, (ii) Protected forest and (iii) Unclassified forest. ${ }^{5}$ The Annual Administrative Report of 200708 indicates that "Out of the total forest area in the State, the area under Reserved Forests including Wildlife Protected Area Network is 1,467 sq. km. i.e. $8.4 \%$ of the total forest area. An area of 4,171 sq.kms or $24 \%$ of the total forest area is recorded as Protected Forests and the rest 11,780 sq. kms $(67.6 \%)$ is categorized as "unclassified forests". 6

The Annual Administrative Report 2007-08 mentions that according to the State Forest Report 2005, the forest cover of Manipur is 17,086 sq.kms which is $76.53 \%$ of the total geographical area of the State, as 
against 17,259 sq.kms in 2003 indicating a net loss of 173 sq.kms in the forest covers during the period. Such large amount of decreased in the forest cover is attributed to the practice of shifting cultivation and flowering of bamboo in the districts of Tamenglong, Churachandpur, Chandel and Jiribam sub-division. ${ }^{7}$ Another forest report clearly indicates that the forest area in Manipur is gradually declining from 1989 onwards till 2002-03. ${ }^{8}$ Similarly, the State of Environment Report indicates that the degradation of forests is on the rise with a loss of 759 sq. km. forest covers during 1991 to 2001 in Manipur i.e., annual average loss of 75.9 sq.km. ${ }^{9}$ Further the Forest Report shows that the state has a high incidence of deforestation of about 0.04 percent that is well above the national and international average which is considered very disturbing in the ecology. ${ }^{10}$ The examination of the district wise data reveals that the dense forest cover is reportedly increasing in Ukhrul and Tamenglong districts, while Senapati, Churachandpur and Chandel shows declining. ${ }^{11}$

But according to the latest source of E-pao a daily e-news (dated, $8^{\text {th }}$ Feb. 2012) reported that among the districts of Manipur; Senapati and Ukhrul ranks first and second in deforestation with 120 sq.km and 98 sq.km lost of forest cover, contributing the lost due to increase in jhum cultivation. ${ }^{12}$ Such declined in forest cover and ecology is closely followed by Chandel, Churachandpur and Tamenglong districts.

\section{Some Factors Responsible For Deforestation And Destruction Of Social Ecology}

Felling of trees for logging, firewood and for various purposes by the hill dwellers of Manipur has been in practice for many years. But the excessive commercial exploitation of forest trees for logging even to the remotest region has resulted to substantial increase in deforestation, while on the contrary the forest department incurred huge revenue from it every year since there are no strict mechanisms to control the problem. The state is now under serious pressure from social ecological imbalances. The above forest and environment reports indicates that the main cause of deforestation, environmental degradation, soil erosion, disturbance in foodchains and decline of flora and fauna in Northeast India is mainly attributed to the traditional shifting/ jhum cultivation, felling of timber for commercial purposes, for firewood and other domestic usages. ${ }^{13}$ These factors are primarily considered as the outcome of increase in human population and developmental works or urbanisation. As a result they may be attributed as the root cause for the entire disturbance in the social ecology and jeopardizing the food-chain of various flora and fauna and the livelihood of the rural tribal people whose main sustenance depend on forestry. On the above criteria, certain important factors responsible for the degradation and deterioration of social ecology in Manipur may be analysed below:

i. Increased Human Population: According to 2011Census of India, the Manipur population is 27.21 Lakh, (i.e.: 27, 21,756), an increased from 22.94 Lakh of 2001 census, a total decadal growth of 18.65 percent, more than 4 lakhs. Such rapid increase in human population is considered the most important detrimental socioeconomic factor for many developed and developing countries of the world. The increase in human population directly resulted in the increase of consumerism, increase demand of goods and services or production, increase in demand for land space, increase in deforestation and environmental degradation besides many others. The State Environment Report too claimed that the main driving force for the destruction of forest and biodiversity in Manipur is the high rate of population growth. ${ }^{14}$

ii. Increased in Developmental Work: The increase in developmental works, urbanisation or industrialisation has been the main outcome of tremendous increase in uncontrolled human population. With increase population there are more mouths to feed, more land spaces required for housing, farming, quality and quantity developmental infrastructure, etc. which are all vital in the expansion of the human settlements. For example, roads expansion, construction of Tipaimukh Hydel Project, construction of North Cachar-Imphal Railway. ${ }^{15}$ The State Environment Report clearly pointed out that "The destruction of forest and biodiversity in Manipur is the result of excessive deforestation for firewood, timber and encroachment of forest land multifarious and developmental works like establishment of housing colony, road construction, dam construction, etc. These are the effects of population growth, which gives a great pressure on forests and biodiversity". ${ }^{16}$

iii. Shifting/ Jhum Cultivation: Northeast being a hilly region with many ethnic tribal communities often practices their traditional shifting/ jhum cultivation for planting paddy, cash crops, fruits and vegetables. This practice is one of the most common factors pointed out by the forest and environment departments for the cause of environmental degradation and declined in forest areas in the Northeast India, for it does not give enough time for the forests to grow back and the soil to renew its fertility. The peculiar feature of shifting cultivation is that the people after using the particular area for 3-4 years shift to another hill slope for cultivation. According to Tarik Yuhlung of Khongkhang Chothe village (Village Chief) the reason for frequently shifting their cultivated land time to time is that "if they did not shift the jhum field after a period of 3-5 years usage, the land did not yield a good harvest. So, they are compelled to shift to fertile sloppy area from time to time to increase their production, where they even returned to the earlier area after 15-20 years". In this way, the old land is left to regenerate itself for certain years, while new forest slopes are chosen and cleared for the next shifting 
cultivation. Thus, with the increase in human population the size of shifting/ Jhum area increases in proportion to their economic constraint.

So, most forest and environmental reports indicated that the main cause for the increase deforestation in Manipur during the last 20 years was due to the traditional Jhumming or shifting cultivation. Rajiv Ranjan and V.P. Upadhyay in their Orissa study stated that "The current practice of shifting cultivation in eastern and North Eastern regions of India is an extravagant and unscientific form of land use. The evil effects of shifting cultivation are devastating and far-reaching in degrading the environment and ecology of this region. The earlier 15-20 year cycle of shifting cultivation on a particular land has reduced to 2-3 years now. This has resulted in large-scale deforestation, soil and nutrient loss, and invasion by weeds and other species. The indigenous biodiversity has been affected to a large extent."17

But contrary, to the above statements, some scholars in their intensive study found out that so long as the shifting/ jhum cycle has duration of 10 years or more this type of cultivation did not pose any threat to the ecological stability and soils of the largely forested hill area. ${ }^{\mathbf{1 8}}$ In support, jhum fields are immediately replaced with a new kind of vegetation, and when abandon it renew naturally again, since the trees and shrubs grown in such jhum fields were not completely uprooted, unlike felling timbers. In certain cases, the abandon jhum fields are used again by the people after few years, so it is term cyclical or rotational. On the other hand, shifting/ jhum farming is more like an organic farming, since no artificial fertilizers are used unlike the terrace or wet cultivation which are prone to health hazard.

So, in general the impact of shifting cultivation to the social ecology may be considered as having less impact or damaging compared to felling of timbers for commercial purposes since the area is immediately replaced with different vegetations.

iv. Expansion of Village Settlements: With the rapid increase in human population and urbanisation, there arise the expansion of human settlements both in rural and urban areas, where land are encroached for housing, farming or agriculture, roads and other developmental purposes. All the hill districts come under the Autonomous Hill District Council Acts, and this act has given ample authority to the traditional local village chiefs over the land in the hill area. But there are no proper legal regulations on the preservation of forest areas. Hence, the partial or semi-forest and even the dense forest areas are being encroached resulting in the increase exploitation of land and natural forest resources in order to sustain their livelihood. This needs no further explanation, every year the cities are expanding with the increase in human population, so also the towns and villages even in the rural areas.

v. Commercial Exploitation of Forest Plants: The State of Environment Report indicates that the forest cover area increases during 1980's to early 1990's but began to decline from 1990's and still continues to be. ${ }^{\mathbf{1 9}}$ In case of Manipur, the commercial exploitation of forest plants may be attributed broadly into three types: (a) Felling of timbers for commercial purposes, (b) Felling of forest trees for domestic firewood and (c) Felling of forest trees for brick kiln firms, which are detrimental to social ecology.

(a) The Felling of Timbers for Commercial Purposes: Perhaps, if one makes a visit to the hill districts of Manipur, one will notice that there are hardly any dense forests or huge trees that are more than 200/300 years old, although small portions of dense forest are located in the very interior part of the region i.e. partly in Ukhrul and Tamenglong where no vehicles could tread into. So, the existing partial or semi-partial forest covers is said to be partly due to Government intervention. But the worst affected hill districts of Manipur from deforestation are Senapati, Churachandpur, Chandel, Ukhrul and Tamenglong (see reports and satellite image, Map). The decline of dense forest in the region began with the introduction of modern trucks during 1970-80's which enable to exploit and transport in large quantities of huge timbers and logs for commercial purposes to neighboring states. Such extensive uncontrolled commercial exploitation for timber and firewood have drastically reduced the size of the dense forest cover of all hill districts of the Manipur, thereby disturbing the social ecology and habitat of various plants and rare indigenous wildlife species.

With regards to Northeast in general, The Shillong Times (dated; 23 May 2012, p-3,10) reported that illegal felling of trees is going on in large quantity in East Garo Hill and West Khasi Hill districts of Meghalaya. The caption of the newspaper reads as "GSU concerned over 'alarming' deforestation", stating that Garo Student's Union (GSU) expressed their concern over the rate of deforestation through rampant felling of trees in Garo Hills by saw mill owners exporting wood to others states. Further, it points out that there is increase illegal installation and operation of saw mills in dense forestation which is depleting the forest cover and destroying the indigenous species of trees that is protected by the State government and Autonomous District Councils under the purview of the Meghalaya Tree Felling (Non Forested Areas) Act $2006 .^{20}$

Similarly, The Shillong Times reported again about illegal logging with a picture. Below it reads as "Illegal logging on in Rambrai in West Khasi Hills. Illegal logging, which is complex problem, threatens the future of forests of Meghalaya". ${ }^{21}$ Such are few reports made known but there are many unreported cases where 
such incidents of timber smuggling business are going on among the North Eastern states, where some local leaders and forest officials are believed to be indirectly involved.

(b) Felling of Forest Trees for Domestic Firewood: Since majority of the people lived in rural areas it is most probable that they depend on natural forest resources to sustain their livelihood, the worst sufferers being the womenfolk. It is reported that more than $80 \%$ of the population depends on firewood as its major fuel for cooking purposes. ${ }^{22}$ Although most of the hill tribes' felled trees either for house construction, furniture or cooking purposes its consumption is believed in small quantity as compared to the valley whose population is exceedingly higher due to huge population. Moreover, almost the entire Manipur valley people depend on the hill tribes for timber, firewood, charcoal and other forest produces. For example, the valley people requires timbers, logs, firewood and charcoal either for domestic cooking purposes, cremation, furniture, hotel's cooking, marriages and feast cooking, even for brick kiln firms, etc. The demand for firewood and charcoal increases because of the irregular supply of cooking gas and electricity in the state, thereby felling of forest trees by the local tribes is on the rise to gratify their economic constraint.

(c) Felling of Forest Trees for Brick Kiln Firms: Of late, felling of forest trees for brick kiln firms and even candle manufacturers in Manipur is on raise. The number of brick kilns in the state is believed increasing with urbanisation or increase in various developmental works. ${ }^{23}$ The increase demand of firewood by the brick kiln firms is due to the fact that firewood is available in plenty, cheaper and serve more economical than coal which is not available in the state. In Chandel district, normally each community has their own reserved village forest areas so also in other tribal hill areas. Such forest cover is permitted to fell or harvest timber or firewood only when a consensus opinion is reached between the village chief and the villagers. So, the traditional felling of forest trees for firewood by a community is done usually after a period of 10-15 years gap when the tree attained certain size. But nowadays since the demand for supply of firewood increases for domestic cooking and brick kilns the poor hill dwellers have began to harvest their forest trees before 5 years in order to sustain their livelihood.

Besides these factors, there are many others which have led to drastic social change affecting directly or indirectly the rich biodiversity, the social ecology and socio-economic conditions of North-eastern region resulting in the destruction and deterioration of social ecology and jeopardising the livelihood of the hill tribes where the government needs to intervene.

\section{Some Major Issues On Critical Depletion Of Ecology}

The consequences of deforestation or excessive commercial exploitation of forest trees have resulted into many minor and major social and environmental issues especially in Manipur. Certain issues that pose a threat to social ecology may be discussed below.

(i) Decline in Flora and Fauna: Many rare indigenous flora and fauna species of the state are considered declining every year, as their habitat are being disturbed. A disturbance in a food-chain of a species resulted in the disturbance of food-web is a well known fact. The state's forest and environment reports indicate the number of wildlife, insects and birds like deer, jungle fowl, wild boar, sangai or the brow antlered deer, serow, clouded leopard, golden cat, hoolock gibbon ape, himalayan bear, hog-badger, slow loris including Javan Rhinoceros and wild ox from Myanmar which were abundantly available in the past is said to be fast becoming extinct in the state. These extinctions are a result of rapid deforestation and destruction of their habitat despite the prevalence of in-situ and ex-situ protection mechanisms. ${ }^{24}$

It is reported that in Manipur there are more than 104 species of animals (fauna) used as age old medicine and more than 5000 Sacred Groves. Further it states that these animals of ethno-zoological importance are in threat due to over exploitation and the sacred Groves are disappearing too. ${ }^{25}$ In olden days the hill tribes/ dwellers used various grass, herbs, creepers (flora) and other forest plants as medicine in the treatment of various ailments. But now, with the increase in deforestation and destruction of natural habitat such rare and invaluable herbal plants are declining. Had the Forest and Environmental Departments maintained a frequent awareness campaign on the value of rich biodiversity by keeping a strict vigilant on excessive felling of trees and killing of wild animals, birds and insects beyond the rate of its reproduction many rare species of flora and fauna could have been saved from extinction. It is reported that Rs. 53.94 lakhs was spent under 'Preservation of Wild Life', but unluckily it was spent only on the sanctuaries. ${ }^{26}$ It is also reported that a common phenomenon prevails in this state where certain plants and animals are illegally exported to foreign countries like Agar, Cinnamonum, and Smilax. Timber species and animals like Malayan Sun bear, Pangolin, etc. are considered to be in high demand, but the government pays no attention.

(ii) Soil Erosion: With the increase in deforestation and shifting cultivation in the hill districts soil erosion increases too. So, every year the Loktak Lake is filled with huge amount of humus, dirt and siltation from the rivers and tributaries flowing into the lake, especially during the monsoon season. The forest report claimed that a total of 50 per cent of the soil loss is accumulated in the lake every year i.e. 6, 36,325 tonnes every year and an 
annual siltation of 4.50 hectare meters per $100 \mathrm{sq} . \mathrm{km}$ a year. ${ }^{27}$ To check the soil erosion various places undertaken by the state for afforestation and reforestation programs are identified only in the feasible areas instead of the vulnerable hill/ valley areas (see the reports data).

(iii) Scarcity of Drinking Water: The town of Ukhrul is like a bald head where only few shrubs are seen grown with poor vegetation. Moreover, the hill towns of Ukhrul and Senapati are facing the problem of scarcity of drinking water, where the people are buying water from nearby localities because there is not enough water in the reservoir to supply. Insufficient water sources in these towns are attributed to decline in forest or big trees in the region. Similarly, Chandel, Churachandpur and Tamenglong districts are seen facing the same problem. It is considered that each year the amount of water in the rivers, streams, tributaries and springs that originates in the hills are decreasing, so also the varieties of aquatic organisms and fish due to deforestation. The scarcity and decline of water sources in the hill districts and valley of Manipur are due to excessive felling of huge/ big trees for timbers which act as water tapping source. Big trees are believed to be capable of absorbing and retaining the rain water by its roots, besides providing cool shade and more oxygen in the area. In Meghalaya, Ladrymbai (near Jowai) is another town where people are facing this water shortage crisis due to change in their landscape from excessive unscientific coal mining and with no forest covers around it.

(iv) Weaknesses of the Forest and the Environmental Department's Officials: The decline in forest cover and depletion in ecology may be attributed to the weaknesses and failure of the Forest and Environmental Officials, Manipur as they failed to carry out their duties and responsibilities seriously. The statistical data in the Annual Forest Reports of Manipur of 2007-08 points out that since 1989 the forest cover in the hill districts of Manipur had been gradually declining. ${ }^{28}$ Further, the report indicated a total amount of Rs. 32, 76.49 lakhs was spent under Non-Plan, Plan and Centrally Sponsored Schemes during 2007-08. Under this scheme the project on soil and water conservation spent Rs. 98.98 lakhs for afforestation; Rs. 15.98 lakhs was spent for rehabilitation of only 24 Jhumians household families, etc. ${ }^{29}$

Besides, many successful projects, the contradiction observed in the study is that the places covered under various schemes of afforestation, soil and water conservation, wildlife sanctuaries and national park preservation are mostly located and identified in the valley areas and in few feasible hill areas, instead of mainly focusing on critically depleting hill forest areas. ${ }^{30}$ Increase in soil erosion, siltation of lake, scarcity of water and imbalance in food-chain and food-web of flora and fauna are pointed out due to gradual deforestation from the hill areas, if so, why is the government not implementing such schemes more in those critically depleted hill forest zones than in the valley areas. Even the afforestation programs in the hill areas are taken up only in such places where the officials can carry out their task easily rather than identifying the actual depleted forest zone in the interior part of the state. This significantly suggests the insincerity, weaknesses and failure of the government machineries in their assigned duties as responsible persons.

(v) The Scheduled Tribes and Other Traditional Forest Dwellers Act: The tribal forest act is considered one of the major hurdles for the officials in implementing various forestry schemes and projects in the hill districts. The reason being that the forest areas in the hill districts are maintained and managed by the local villagers, where each tribes or locals have full right over their forest land as guided by the Autonomous Hill District Council acts. ${ }^{31}$ But the new forest rights of "The scheduled tribes and other traditional forest dwellers (recognition of forest rights) Act. 2006" has given more room for the hill tribal in accessing their forest areas. But such acts cannot be misunderstood by both the hill tribes and valley people in the implementation of certain regulation related to the control of deforestation, soil erosion and preservation of biodiversity - flora and fauna. Since, there are certain provisions in the tribal forest acts where negotiation can be reached out between the locals and government officials in solving the problem of deforestation and destruction of social ecology. The government however, has to make sure that the power and authority of the local leaders does not act in contrary to the desired goal.

\section{Challenges And Opportunities To Overcome The Destruction Of Social Ecology}

Manipur has been considered as one of the most unproductive states in the region for the past two decades because of its ongoing unstable socio-political conditions i.e. unending insurgency problems, unscrupulous activities of the government functionaries and frequent agitations from the pressure groups. The rural hill tribes are being accused for the rapid destruction of social ecology. On this basis, various NGO's and government bodies have been organising awareness programs and other rural sustainable developmental programs in relation to afforestation, reforestation in order to conserve, preserve and improve the social ecology. But, despite certain successes, the problem of deforestation and social ecology still persists at large in the state. The rural hill people continue to be deprived of the opportunities due to inappropriate application, negligence and implementation of various programs.

a) Afforestation and Reforestation: Joyotee Smith defined forests as having a tree crown cover greater than $10 \%$. While afforestation and reforestation differ only in that, the activity will be afforestation if the land 
on which it takes place had not been forested for at least 50 years, whereas reforestation refers to land that did not contain forest before $1990 .^{32}$ The plants introduced in afforestation programs for conservation of soil and water, and preservation of bio-diversity are new foreign plants like pinus, eucalyptus, teak and others which are considered high yielding and has high commercial value as timbers. But these new foreign plants are considered destructive to the soil and unfavorable to various endangered flora and fauna besides having only one life cycle, unlike the indigenous plants which are eco-friendly and regenerate it after certain years. With regards to forest management, Manipur should follow the policy of Tripura, Sikkim, Assam and Nagaland as these Northeast states are seen doing better in the conservation and preservation of their forest covers. For mixed forest covers many selected indigenous plants should also be considered in the afforestation programs.

b) Restriction and Identifying Area on Foreign Plants: The foreign plants like pinus and eucalyptus should be restricted to certain extend in the afforestation and reforestation programs. The soil surrounding such plants is considered acidic and infertile for the growth of grasses, shrubs and other plants around it. Moreover, these foreign plants are not attracted or preferred much by birds, animals and insects as it does not bear fruits or nuts and so it does not contribute in their food-chain and food-web processes. Thus, Manipur government should stop large scale plantation and supply of such saplings (especially eucalyptus) to the locals, since it has been discouraged in Indonesia for soil toxicity. Besides, the hill forest is now fill with pinus as abundantly grown in most hill districts due to high commercial timber value. The government should rather first survey and identify certain barren land, waste-land or water-shed areas and carry out the plantation of such plants only after scientifically examining the soil for its suitability.

c) Horticulture Plants: The hill tribes were once considered self-sufficient in food grains and horticulture products like corns, rice, maize, yam, banana, orange, lemon, mango, pineapple, jack fruits, papaya, pear, sugarcane, turmeric, ginger, bean and younchak/ monkey-rice as grown especially in their garden and jhum fields. But nowadays with their urban attitudes, there is a sharp decline in plantation and production. Yet, since the region is located in a hot tropical zone and is considered favourable for such horticulture plants, the government and NGO's should encouraged the rural people for such plantation to meet the needs of the local markets, as well as to increase the economy of the people in the state.

d) Bamboo Plants: Different hill tribes plant varieties of bamboo species in and around their settlements for various purposes, which is really benefits them a lot. But since there is no bamboo factory or industry in the state, large scale/ commercial bamboo plantation does not yield much a good result. Instead of bamboo, agro and plants like alder tree (Alnus nepalensis), cinnamon tree, woody species (yucca, cashew), etc, along with other indigenous plants should be encouraged by providing free saplings to the rural tribes as these plants do have high commercial values. ${ }^{33}$

e) Intervention Through MGNRGES: In the afforestation and reforestation programs the Govt. can intervene in the local forest management through Mahatma Gandhi National Rural Guarantee Employment Scheme (MGNRGES) by giving them the opportunity of tree plantation.Like Mizoram, micro enterprises including promotion and modernization of small scale and cottage industries should be encouraged to the rural tribal people through MGNRGES or local co-operative societies or organisation. ${ }^{34}$ The value of horticulture and animal husbandry should be encouraged and given more emphasis.

f) Spread More Awareness of Social Ecological Consequences: Various participatory awareness programs on social and ecological degradation should be frequently conducted by Govt. and NGO's among the rural people in order to counteract as a challenge to the issues of deforestation, global warming and environmental degradation. Various technical and practical programs should also be checked and managed regularly from time to time.

g) Application of Sixth Schedule in Manipur: The conflict between the Government and the indigenous tribes can be amicably solved if the Government seriously intervene and formulate appropriate amendments to the forest acts and policies with certain provisions. The forest report suggested that the Autonomous District Councils Act 1971 should be amended to solve territorial disputes between the state and tribal groups by making the councils solely responsible for settlement of land tenures that include customary and collective tenures. ${ }^{35}$ For example, the Arunachal forest policy states that the new policy dated $1^{\text {st }}$ June 1990 was on involvement of village communities and voluntary agencies in the regeneration of degraded forest lands. ${ }^{36}$ So, the local village chiefs and local leaders should be given certain power to exercise their authority over their community forest rights as local forest guardians and also providing some incentives in order to check the excessive exploitation of natural resources from the unclassified forests.

\section{Conclusion}

The above description shows a contradiction in the state's reports. The various sources have pointed out that there has been a gradual deforestation in the state since 1990's onwards, and declined in the harvests of wood and non-timber forest products since 1995, but nothing serious steps have been taken up so far by the concern departments. ${ }^{37}$ Problems like increase human population, increase developmental works, urbanization, 
unchecked commercial exploitation of timbers, etc. are considered as the main causes for tremendous deforestation, environmental degradation and global warming, giving rise to increase social, economic and ecological problems like imbalance in social ecology, disturbance in food-chain and food-web, declined in indigenous flora and fauna, scarcity of drinking water that threatens the livelihood and sustainability of the rural (tribal) people. Despite huge investment to improve the forest condition of the state with various afforestation and reforestation programs, water and soil conservation, it rather shows retrogression. The regression is that the major problems are located in the rural hill areas, but the government of Manipur deliberately neglects and failed to focus their attention in implementing numerous schemes designed to counter this serious depletion of the hills forest areas. Instead, the schemes meant for the hills are directed towards the valley areas and to only some feasible hill areas. Therefore, the state could not progress in the desired direction of development as projected and expected. The worst affected people identified are those tribals who live in rural areas rather than those living in urban areas. The crisis of this magnitude requires the officials of the State's Forest and Environment Departments, Manipur, Water and Soil Conservation to jointly work together strategically by seriously sorting out combine future programs applying scientific and methodological applications, without menacing the rural economy. Trees and river water have become extremely scared in the state. If the Forest Department of Tripura, Arunachal Pradesh and Nagaland can checked the felling of trees; why not the state of Manipur? It is on this outset that certain challenges and opportunities are being highlighted and addressed in the rural development programs for proper forest and environmental management in order to uplift the rural people whose main source of economy depends on forestry for their sustenance in the forest produces. It is also anticipated that the "Kyoto Protocol" a treaty on reduction for carbon monoxide or Global Warming could somehow materialised and benefit the region through their policy and program in the future as green peaceful state. $^{38}$

Table -1 Change in the Forest Cover in Manipur (Sq. Km) 1991-2001

\begin{tabular}{|l|l|l|l|}
\hline Year & Forest Area (Sq. Km.) & Years & Changes (Sq. Km.) \\
\hline 1991 & 17685 Sq.km & $1991-93$ & $\mathbf{- 6 4}$ \\
\hline 1993 & $17,621 \mathrm{Sq} \cdot \mathrm{km}$ & $1993-95$ & $\mathbf{- 6 3}$ \\
\hline 1995 & $17558 \mathrm{Sq} \cdot \mathrm{km}$ & $1995-97$ & $\mathbf{- 1 4 0}$ \\
\hline 1997 & $17418 \mathrm{Sq} \cdot \mathrm{km}$ & $1997-99$ & $\mathbf{- 3 4}$ \\
\hline 1999 & $17,384 \mathrm{Sq} \cdot \mathrm{km}$ & $1999-2001$ & $\mathbf{- 4 5 8}$ \\
\hline 2001 & $16926 \mathrm{Sq} \cdot \mathrm{km}$ & $2001-03$ & $\mathbf{+ 2 9 3}$ \\
\hline 2003 & $17219 \mathrm{Sq} \cdot \mathrm{km}$ & $\mathbf{1 9 9 1 - 2 0 0 3}$ & $\mathbf{- 4 5 6}$ \\
\hline
\end{tabular}

Source: FSI (see State of Environment Report, Manipur. Chapter- IX, p:109)

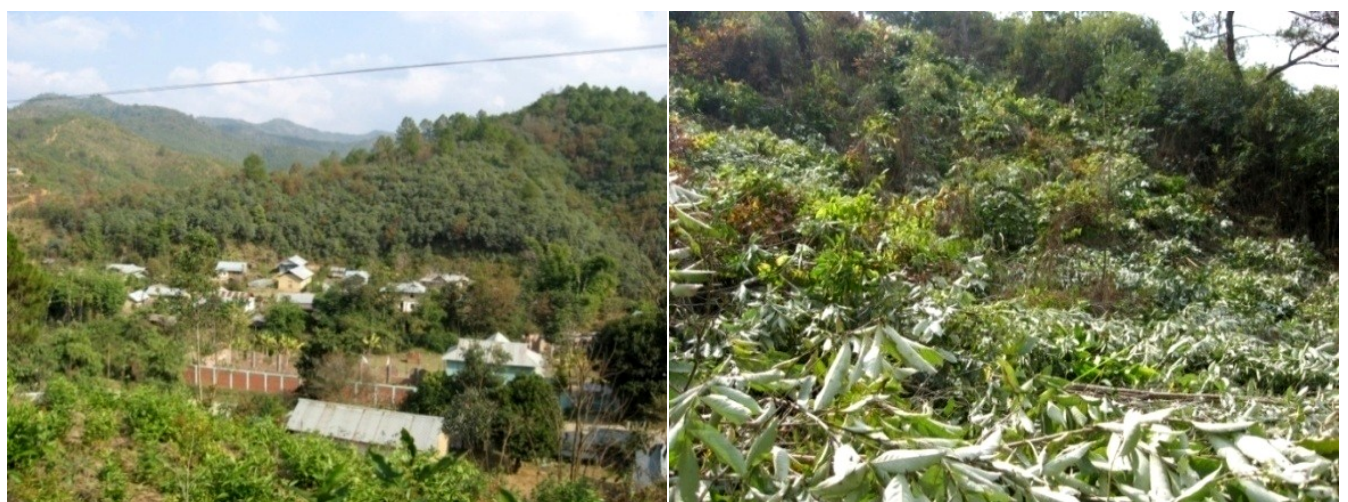

Pic.1 Typical indigenous forest in Chandel, Manipur

Pic.2 Harvesting indigenous forest plants
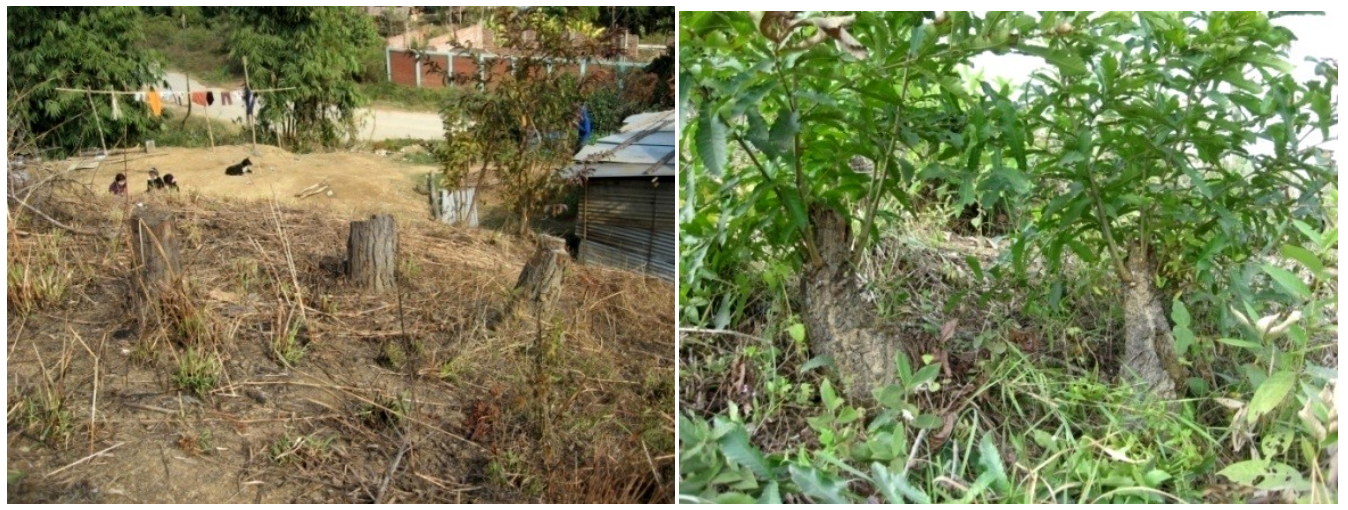


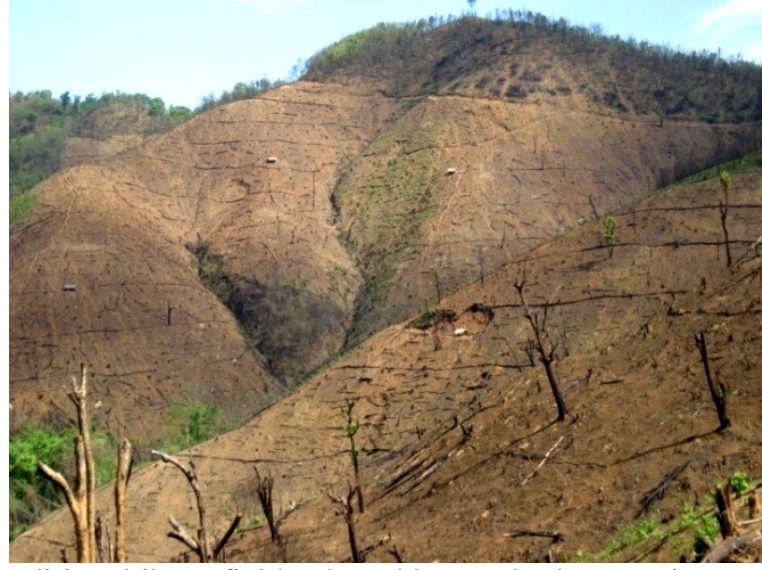

Pic.5 Traditional jhum field, Khongkhang Chothe, Manipur

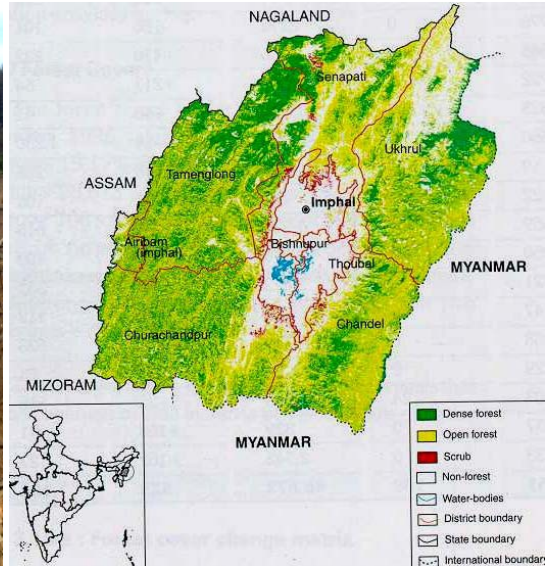

Pic.6 State of Environment Report, Manipur. $\mathrm{p}: 122$.

\section{Acknowledgment}

I thank Mrs. Nila Dutta and Mrs. Pr. Dimchuiliu, Dept. of Sociology, faculty of Women's College, Shillong for their kind invitation and encouragement in writing this paper for 'Rural Development in North East India: Challenges and Opportunities' on $27-28^{\text {th }}$ July 2012. I also thank my local Chothe informants who provided me their invaluable information during my PhD fieldworks without which this paper would not have been made possible.

\section{Endnotes}

\footnotetext{
1 North Eastern Region Vision 2020 p:5

2 Census of India, Manipur 2001

${ }^{3}$ The nine districts of Manipur are as - the five hill districts comprise: Senapati, Ukhrul, Tamenglong, Churachandpur and Chandel, while the four valley districts are: Imphal East, Imphal West, Thoubal and Bishnupur respectively.

4 State of Environment Report, Manipur, Chapter -IX. p: 108

5 Annual Administrative Report 2007-08: 4

6 Annual Administrative Report 2007-08: .

7 Annual Administrative Report 2007-08: 4

8 State of Forests in Manipur, Chapter - V, 5.I: Status of Forests. p:59).

9 State of Environment Report, Manipur, Chapter -IX. p: 109.

10 State of Forests in Manipur, Chapter - V, 5.I: Status of Forests. p:60.

11 State of Forests in Manipur, Chapter - V, 5.I: Status of Forests. p:59.

12 E-pao, dated, $8^{\text {th }}$ Feb. 2012

13 Rajiv Ranjan and V. P. Upadhyay,1999. (http://www.ias.ac.in/currsci/nov25/articles12.htm)

14 State of Environment Report, Manipur, Chapter -IX. p: 108.

15 State of Forests in Manipur, Chapter - V, 5.I: Status of Forests. p:62.

16 State of Environment Report, Manipur. Chapter-IX. p:109-110.

17 Rajiv Ranjan and V. P. Upadhyay. 1999. (http://www.ias.ac.in/currsci/nov25/articles12.htm)

18 Land Use and Jhum Cultivation in Manipur. Chapter -VI. p: 82

19 See, State of Environment Report, Manipur. Chapter-IX and Annual Administrative Report 2007-08.

${ }^{20}$ The Shillong Times. Dated: 23 May 2012, p-3,10.

21 The Shillong Times.Dated: 6 June 2012. (Front page right column picture).

22 State of Forests in Manipur, Chapter - V, 5.I: Status of Forests. p: 69.

23 State of Forests in Manipur, Chapter - V. p: 69.

24 State of Forests in Manipur, Chapter - V, 5.I: Status of Forests. p:58.

25 Annual Administrative Report 2007-08. p:8.

26 Annual Administrative Report 2007-08. p:8.

27 State of Forests in Manipur, Chapter - V, 5.I: Status of Forests. p:61.

28 State of Forests in Manipur, Chapter - V, 5.I: Status of Forests. p:59.

29 Annual Administrative Report 2007-08: 6
} 
${ }^{30}$ See in the Annual Forest Reports 2007-08 and State of Environment Report, Manipur.

${ }^{31}$ State of Forests in Manipur, Chapter - V, 5.I: Status of Forests. p:57.

${ }^{32}$ Smith, Joyotee, 2002. p:323. (Koyoto protocol)

${ }^{33}$ Land Use and Jhum Cultivation in Manipur. Chapter -VI. p:85.

${ }^{34}$ Executive summary of new land use policy (Nlup) project: I (Mizoram govt. exesummary).

${ }^{35}$ State of Forests in Manipur, Chapter - V. p:73.

${ }^{36}$ G.N. Sinha. 2006. (www.sfri.orgimagesgeneralarticle_cfm.pdf)

37 State of Forests in Manipur, Chapter - V, 5.I: Status of Forests. $p$ :69.

${ }^{38}$ The Kyoto Protocol treaty was negotiated in December 1997 at the city of Kyoto, Japan and came into force February 16th, 2005. The Kyoto Protocol is a legally binding agreement under which industrialized countries will reduce their collective emissions of greenhouse gases by 5.2\% compared to the year 1990 (but note that, compared to the emissions levels that would be expected by 2010 without the Protocol, this target represents a $29 \%$ cut). The goal is to lower overall emissions from six greenhouse gases - carbon dioxide, methane, nitrous oxide, sulfur hexafluoride, HFCs, and PFCs - calculated as an average over the five-year period of 2008-12. National targets range from $8 \%$ reductions for the European Union and some others to $7 \%$ for the US, $6 \%$ for Japan, $0 \%$ for Russia, and permitted increases of $8 \%$ for Australia and $10 \%$ for Iceland. Kyoto Protocol summit addresses the issue of 'Clean Development Mechanism' (CDM) for the afforestation and reforestation for the forest people of the world on the issue of increase global warming. But some developed countries were not willing to part the huge financial assistant required for afforestation in the select developing countries like India, Indonesia this created conflict and slow down the policy for implementation. (From Wikipedia, the free encyclopedia).

[1]. Annual Administrative Report 2007-08. Forest Department Government of Manipur, Accessed on: 7/7/12. p:1 -12

[2]. E-Pao, a daily e-news of Manipur, dated: Today- Saturday, July 07 2012. 'Manipur's forest covers depleting rapidly'. (Source: Hueiyen New Service, Imphal, February 08-2012).

[3]. G.N. Sinha. 2006. Prospects of Community Forest Management and Role of Panchayats in Arunachal Pradesh. Published in SIRDARUN, Annual Journal of Rural Development, Volume 1, June, Itanagar.(Pp: 1-9). (Worked in State Forest Research Institute, Itanagar, Community forest- Arunachal Pradesh). www.sfri.orgimagesgeneralarticle cfm.pdf, accessed on: 23/3/12.

[4]. Land Use and Jhum Cultivation in Manipur. Chapter -VI. Land use and jhum cultivation in Manipur: Problems, prospects and alternatives (Pp:77-90). wwwplanningmanipur.gov.in, accessed on: 23/3/12

[5]. New Land Use Policy, Executive summary of new land use policy (NLUP) project. (Pp: i-xvii). (www.Mizoram govt. exesummary), accessed on 23/3/12.

[6]. North Eastern Region Vision - 2020. Volume 1. Ministry of Development of North Eastern Region \& North Eastern Council, Pp:1 293, accessed on: $4 / 5 / 12$

[7]. Peter J Kanowski1 2002. 'Afforestation and plantation forestry Plantation forestry for the 21st century', in Afforestation and plantation forestry. Vol. 12. (Pp:1-84).

[8]. Rajiv Ranjan and V. P. Upadhyay. 1999. Ecological problems due to shifting cultivation. Accepted 6 August 1999. (The authors are in the Ministry of Environment and Forests, Eastern Regional Office, Bhubaneswar -751 001, India). http://www.ias.ac.in/currsci/nov25/articles12.htm. Accessed on 23-3-2011.

[9]. Smith, Joyotee. 2002. 'Afforestation and reforestation in the clean development mechanism of the Kyoto protocol: implications for forests and forest people', Int. J. Global Environmental Issues, Vol. 2, Nos. 3/4, pp.322-343. Accessed on: 23/3/12

[10]. State of Environment Report, Manipur . Environment and Ecology Office Government. of Manipur. Chapter -IX. (www.man envis.nic.in SOE 20 Report Chapter9.pdf. Accessed on: 7/7/12.

[11]. State of Forests in Manipur, Chapter - V, 5.I: Status of Forests. (Pp:56-77). www.planningmanipur.gov.inpdfMSDR Chapter 205_Forestry.pdf), accessed on 7/7/12

[12]. The Gazette of India, Extraordinary, Part-II, Section-I, Ministry of Law and Order, "The Scheduled Tribes and other Traditional Forest Dwellers (Recognised by Act, 2006). Published by Authority. New Delhi, 2 January 2007. www.Tribalforest act.pdf, accessed on $12 / 8 / 11$.

[13]. The Shillong Times. Dated: 23 May 2012, p-3 \&10.

[14]. The Shillong Times.Dated: 6 June 2012. p:1(Front page right column picture). 